\title{
Influences of Work-Related Variables on Organizational Commitment of Nepalese Employees
}

\author{
Dr. Prakash Shrestha \\ Lecturer, Nepal Commerce Campus, Tribhuvan University, Nepal \\ Dr. Dilip Parajuli* \\ Associate Professor, Bhaktapur Multiple Campus, Tribhuvan University, Nepal
}

\begin{abstract}
The purpose of this study is to examine the influences of work-related variables (organizational climate, supervisory behavior, role conflict, and role clarity) on organizational commitment (attachment, internalization, normative, and continuance). Data was gathered from 10 Nepal Stock Exchange (NEPSE) listed companies. In total, 250 questionnaires were provided to these companies' employees and a response rate of 71.60 percent was achieved. For data analysis purposes, descriptive statistics and multiple regression analysis with stepwise methods were adopted. Organizational climate, supervisory behavior, role conflict, and role clarity were found to have major impacts on organizational commitment. Out of these, the organizational climate was found to be a common predictor of all the commitment components. Therefore, it is required to focus on creating a sound and effective organizational climate to enhance organizational commitment to companies.
\end{abstract}

Keywords: Commitment, Organizational climate, role clarity, role conflict, supervisory behavior

DOI: $10.7176 / \mathrm{EJBM} / 12-32-01$

Publication date: November $30^{\text {th }} 2020$

\section{Introduction}

Many scholars and practitioners have drawn interest in organizational commitment in the field of management. Organizational commitment is not a modern phenomenon, and as such, many scholars have sought to define the word "organizational commitment". The organizational commitment principle is seen as helpful in predicting the actions of workers and in drawing up an organization's blueprint (Tao, Takagi, Ishida, \& Masuda, 1998). Organizational commitment is critical because a high degree of commitment contributes to a variety of desirable organizational outcomes (Chughtai \& Zafar, 2006). The importance of organizational commitment studies seems to be generally accepted (Aranya, Kushnir, \& Valency, 1986; Tao, 1997). Many studies have explored its meaning (DeCotiis \& Summers, 1987; Morrow, 1983; O'Reilly \& Chairman, 1986; Reichers, 1985; Takagi, 1997). Angle and Lawson (1993); Luthans, Baack, and Taylor (1987); Masuda (1997); and Mathieu and Zajac (1990) have discussed antecedents of organizational commitment. Likewise, Ishida (1997); and Mathieu and Zajac (1990) have mentioned the consequences of organizational commitment. Non-committed employees can define the organization in negative terms to outsiders, thus inhibiting the ability of the organization to hire highquality workers (Mowday, Porter, \& Steers, 1982). These findings have significant implications for both organizational theory and management practice.

Organizational commitment has been described as the relative intensity of the identification of a person with a specific organization and participation in it (Mowday et al., 1982). It is an emotional reaction to employee habits, values, and attitudes. It is a psychological condition that reflects the degree of employee affiliation to the company (Meyer \& Allen, 1991, 1997). Organizational commitment is a central determinant of the employee's relationship with his/her employer (Rehman, et al., 2012). It is often associated with the extent or shallowness of an employee's commitment to his or her organization, the pleasure gained from working for that agency, and the desire to remain a part of that organization (Dey, 2012, Shrestha, 2016).

The tremendous change in the political environment has supported to change management style in Nepal. Decent jobs and the structure of seniority are no longer common. In such a situation, we can assume that the attitudes of employees towards their companies will change. Employee loyalty should be a driving force in the growth of businesses and, without it, corporate success cannot be achieved. These discussions support the importance of the study of organizational commitment from the Nepalese perspective. Hence, this study aims to examine the influences of work-related variables on organizational commitment.

\section{Literature Review}

\subsection{Organizational Commitment}

Many pieces of research reveal that there is a psychological bond between the employees and the companies where they work. The employees' commitment to the company reflects this psychological bond (Lovakov, 2014). Thus, this commitment indicates its importance in binding the participant both to the organization and to courses of action, which are important to the target of the commitment (Meyer \& Herscovitch, 2001). This commitment, 
however, may have distinct foundations. A 3-component model of organizational commitment is suggested by Allen and Meyer (Allen \& Meyer, 1990; Meyer \& Allen, 1991). They note that there are three components of organizational commitment: affective commitment, continuance commitment, and normative commitment. In the context of Nepal, some researchers (e.g., Gautam, 2003, Shrestha, 2019a, 2019b) have applied this 3-component model of organizational commitment. However, at an international level, some previous studies (e.g., Takagi, Ishida, \& Masuda, 1997; Tao et al, 1998) built a scale to measure organizational commitment and extracted four components such as attachment, internalization, normative, and continuance.

Attachment Component: It is an attachment to the organization, distinguished by the desire to remain in it; an affiliation with the organization's principles and objectives; and a willingness on its behalf to expend additional effort. The attachment component provides the employees with increased feelings of devotion, belonging, and security. Employees who have an attitude of affective interest are pleased to spend the remainder of their career in their company.

Internalization Component: It involves an internalization of the policy, strategy, and culture of the company (Beck \& Wilson, 2000; Singh \& Gupta, 2015). It is a perceived alignment of goals and values shared by both employees and the company.

Normative Component: It is the sense of responsibility of an employee to continue with the company. This commitment focuses on employee responsibility and/or spiritual connection. The socialization of workers to the aims and ideals of the company creates this commitment (Allen \& Meyer, 1990). Employees remain in the company with deep normative commitment (Meyer, Allen, \& Smith, 1993).

Continuance Component: It is the readiness to stay in an organization because of the investment that the employee has with "non-transferable" investments such as retirement, relationships with other employees, or things that are special to the company. Meyer and Allen (1997) further demonstrate that it is also very difficult for workers with continuing involvement to leave the company. Employees with a deep commitment to consistency must remain in the organization (Shrestha, 2019b).

\subsection{Work-related Variables}

Many work-related variables such as motivation, job involvement, career commitment, job satisfaction, organizational climate, supervisory behavior, role conflict, and role clarity do have an influence on employee commitment. In one study, Matheiu and Zajac (1990) reported that work-related variables such as motivation, job involvement, career commitment, and job satisfaction have an association with organizational commitment. Likewise, some work-related variables like organizational climate (Campbell, Dunnette, Lawler, Weick, 1970), supervisory behavior (Schriesheim \& Kerr, 1974), role conflict, and role clarity (Rizzo, House, \& Lirtzman, 1970) have an influence on organizational commitment. Among these variables, variables such as organizational climate, supervisory behavior, role conflict, and role clarity are considered in this study to analyze their influence on each aspect of organizational commitment (attachment, internalization, normative, and continuance).

Organizational Climate: It is a psychological climate that includes different dimensions such as degree of structure imposed, individual autonomy, considerations/warmth/support, and reward (Campbell et al., 1970), orientation towards development and progressiveness (Payme \& Pugh (1976), timely decision-making, upward information requirement, induction, top management receptiveness, formalization, job pressure, selection criterion, teamwork, chain of command, inter-group cooperation (House \& Rizzo, 1972), trust, cohesiveness, pressure, recognition, innovation, and fairness (Decottis \& Summers, 1987, cited at Madhukar \& Sharma, 2017).

Supervisory Behavior: It is a supportive behavior of supervisors. Landry and Vandenberghe (2009) claim that the appreciation of the qualities of the supervisor imbues a good feeling of actively looking to associate with the supervisor and consequently become loyal to the supervisor. Schriesheim \& Kerr (1974) also argued that supervisory behavior enhances employee commitment.

Role Conflict: When people face inconsistent or contradictory demands, role conflict occurs (Rizzo, House, \& Lirtzman, 1970; House and Rizzo, 1972).

Role Clarity: It is a consistency of the position. It is the degree to which employees have a clear understanding of their roles, duties, and procedures at work (Rizzo, House, \& Lirtzman, 1970).

\section{Research Methodology \\ 3.1 Sample}

Data was collected from employees (including top-level managers to junior level staff) in 10 companies (including 3 commercial banks, 3 development banks, 3 insurance companies, and 1 manufacturing company) listed on the Nepal Stock Exchange (NEPSE). In total, 250 questionnaires were delivered to the employees of these companies. Out of the 250 questionnaires distributed, 179 were completed and returned (105 males and 74 females), providing a 71.60 percent response rate. 


\subsection{Measurement of Variables}

Organizational commitment was measured based on four aspects such as attachment, internalization, normative, and continuance scale adopted from Takagi et al., 1997; Tao et al, 1998). Participants' views on organizational climate were assessed by the scale adopted from Campbell et al. (1970) and supervisory behavior was measured by the scale adopted from Schriesheim and Kerr (1974). Likewise, role conflict and clarity were assessed by the scale adopted from the work of Rizzo et al. (1970). On a five-point scale, each item was measured with answers ranging from "Strongly Disagree" (weighted 1) to "Strongly Agree" (weighted 5).

\subsection{Data Analysis Tools}

Descriptive statistics such as mean and standard deviation (S.D.) were used to analyze the data, while multiple regression analysis was used to investigate the influences of work-related variables on organizational commitment components.

\subsection{Reliability Test}

To test the reliability of the measuring instrument, Cronbach's alpha coefficient was used. The alpha values for the variables were as follows: attachment $(\mathrm{alp}=0.81)$, internalization $(\mathrm{alp}=0.77)$, normative $(\mathrm{alp}=0.82)$, continuance $(\mathrm{alp}=0.83)$, organizational climate $(\mathrm{alp}=0.79)$, supervisory behavior $(\mathrm{alp}=0.91)$, role conflict $(\mathrm{alp}=$ $0.84)$, and role clarity $(\mathrm{alp}=0.87)$. The alpha values surpassed the 0.7 (Pietersen $\&$ Maree, 2008) adequate benchmark.

\subsection{Test of assumptions of the regression model}

Sheehan et al. (2007) believed that if there is normality and typically, in the findings, the regression model could be used to test perceptual data hypotheses. Therefore, this analysis checks the regression assumptions before using the regression model for testing influences.

\subsection{Test of normality}

The normality of data in this analysis is checked using Kolmogorov-Simirnov (K-S). Test results are given in the table below:

Table 1. Kolmogorov-Simirnov (K-S) Test

\begin{tabular}{|c|l|c|c|}
\hline S.no. & \multicolumn{1}{|c|}{ Variables } & Kolmogorov-Smirnov Z & Asymp. Sig. (2-tailed) \\
\hline 1 & Attachment & 4.31 & 0.00 \\
\hline 2 & Internalization & 3.65 & 0.00 \\
\hline 3 & Normative & 4.19 & 0.00 \\
\hline 4 & Continuance & 5.14 & 0.00 \\
\hline 5 & Organizational climate & 6.14 & 0.00 \\
\hline 6 & Supervisory behavior & 5.19 & 0.00 \\
\hline 7 & Role conflict & 3.18 & 0.00 \\
\hline 8 & Role clarity & 3.65 & 0.00 \\
\hline
\end{tabular}

The results indicate that the Kolmogorov-Smirnov Test (K-S test) confirms that the data is normally distributed at a one percent significance level. Accordingly, it is confirmed that the data is normally distributed and that parametric tests can be used for such normally distributed data.

\section{Data Analysis and Results}

Table (2) shows the means and standard deviations for each variable used in the study.

Table 2: Means and Standard Deviations (S.D.)

\begin{tabular}{|c|l|c|c|}
\hline S.no. & Variables & Mean & S.D. \\
\hline 1 & Attachment & 4.03 & 0.94 \\
\hline 2 & Internalization & 4.04 & 0.81 \\
\hline 3 & Normative & 3.66 & 0.93 \\
\hline 4 & Continuance & 4.10 & 0.39 \\
\hline 5 & Organizational climate & 3.53 & 0.81 \\
\hline 6 & Supervisory behavior & 3.31 & 0.78 \\
\hline 7 & Role conflict & 3.63 & 1.01 \\
\hline 8 & Role clarity & 3.27 & 1.05 \\
\hline
\end{tabular}

Employees seemed committed in terms of attachment (Mean $=4.03)$, internalization $($ Mean $=4.04)$, normative (Mean = 3.66), and continuance $($ Mean = 4.10). However, with other facets of work-related variables, they expressed moderate levels of perception. They reported moderate levels of organizational climate $($ Mean $=$ $3.53)$. They also perceived supervisory behavior $($ Mean $=3.31$ ), role conflict (Mean $=3.63$ ), and role clarity 
$($ Mean $=3.27)$ to be at moderate levels.

To examine the influences of work-related variables on organizational commitment a multiple regression analysis is conducted and stepwise methods were adopted in this analysis. Organizational climate, supervisory behavior, role conflict, and role clarity are the predictors included in the study. The regression analysis results are presented in Table (3).

Table 3. Multiple regression analysis of organizational commitment (standardized coefficients)

\begin{tabular}{|c|c|c|c|c|}
\hline \multirow[t]{2}{*}{ Predictors } & Model I & Model II & Model III & Model IV \\
\hline & Attachment & Internalization & Normative & Continuance \\
\hline Organizational climate & $0.371 * *$ & $0.316 * *$ & $0.291 * *$ & $-0.197 *$ \\
\hline Supervisory behavior & $0.280 *$ & & & \\
\hline Role conflict & & & & $-0.173 *$ \\
\hline Role clarity & & $0.269^{*}$ & $0.253^{*}$ & \\
\hline $\mathrm{R}^{2}$ & 0.224 & 0.324 & 0.142 & 0.059 \\
\hline
\end{tabular}

The first model reveals that the organizational climate has a significant and positive impact on attachment $(\beta=0.371, p<0.01)$. The results also show that the supervisor's behavior has a significant and positive impact on attachment $(\beta=0.280, \mathrm{p}<0.01)$. Thus, the results show that organizational commitment in terms of attachment is predicted by organizational climate and supervisory behavior $\left(R^{2}=0.224\right)$. These two variables are the strong predictors of this component.

Model II reveals that the organizational climate has a significant and positive impact on internalization $(\beta=$ $0.316, \mathrm{p}<0.01)$. The results also show that role clarity has a significant and positive impact on internalization $(\beta$ $=0.269, \mathrm{p}<0.05)$. Thus, the results show that organizational commitment in terms of internalization is predicted by organizational climate and role clarity $\left(R^{2}=0.324\right)$. These two variables are the strong predictors of this component.

Model III reveals that the organizational climate has a significant and positive impact on normative $(\beta=$ $0.291, \mathrm{p}<0.01)$. Likewise, the results also show that role clarity has a significant and positive impact on normative $(\beta=0.253, \mathrm{p}<0.05)$. Thus, the results show that normative commitment is predicted by organizational climate and role clarity $\left(R^{2}=0.142\right)$.

Model IV reveals that the organizational climate has a significant and negative impact on normative $(\beta=$ $0.197, \mathrm{p}<0.01)$. The results also show that the role conflict has a significant but negative impact on continuance $(\beta=-0.173, p<0.05)$. Thus, the results show that continuance commitment is predicted by organizational climate and role conflict $\left(R^{2}=0.059\right)$. However, the contribution of these variables is negative and very small.

\section{Discussion and Conclusion}

This study attempted to explain the predictors of four components of organizational commitment (attachment, internalization, normative, and continuance). Four study variables such as organizational climate, supervisory behavior, role conflict, and role clarity are found to have major impacts on organizational commitment. In previous research (e.g., (DeCotiis \& Summers, 1987; Witt \& Beorkrem, 1991; Takagi et al., 1997; Tao et al, 1998), these variables are important predictors of organizational commitment.

The results present that the major indicator of all four components was the organizational climate. This variable was based on relationships in the company with different dimensions like a degree of structure imposed, individual autonomy, considerations/warmth/support, reward, orientation towards development and progressiveness, top management receptiveness, trust, cohesiveness, innovation, and fairness. The findings, therefore, suggested that high levels of attachment, internalization, and normative commitment were displayed by employees who favorably viewed the availability of sound organizational climate in their company. These research findings are consistent with the results of many preceding studies (e.g., DeCotiis \& Summers, 1987; Yoon, Baker, \& Ko, 1994; Takagi et al., 1997; Tao et al, 1998). In comparison, the effect of the organizational climate on the continuance commitment was negative. It may be due to a perception of the costs of leaving the organization. These perceived costs could increase employees' commitment to continuity. They are not likely to think about leaving the company when employees experience a positive organizational environment.

Another powerful indicator of organizational commitment in terms of attachment was supervisory behavior. This variable was focused on personal relationships, as was the organizational climate. It is, therefore, noteworthy that these two factors were both essential attachment predictors. Perhaps personal relationships in the workplace form the foundation for the effect of employees at workplaces.

As one of the study variables, the role conflict had a substantial negative effect on the continuance commitment. If the role of employees was contradictory, it would decrease their continuing dedication to their organizations. Finally, role clarity had a substantial positive effect on internalization and normative commitment as well. It is believed that if their task is straightforward, employees will make an effort for their organization more easily. Likewise, if the role clarity is strong, the task of employees is not uncertain and that makes their job 
easy. Role clarity, thus, strengthens the normative commitment of employees to their companies. Therefore, this variable is also taken as an important variable to enhance organizational commitment at a high level.

To conclude, the work-related variables in terms of organizational climate, supervisory behavior, role conflict, and role clarity are influencing factors on the organizational commitment of employees to their companies. Out of these, the organizational climate was found to be a common predictor of all the commitment components. Therefore, today's companies need to create a sound and effective organizational climate to enhance their employee commitment. Employees generate an important source of competitive advantage for businesses (Shrestha \& Parajuli, 2020). It is, therefore, important for businesses to concentrate on the productive use of human capital and create an environment to make them committed and dedicated to organizational activities.

\section{References}

Allen, N.J., \& Meyer, J.P. (1990). The measurement and antecedents of affective, continuance and normative commitment. Journal of Occupational Psychology, 63(1), 1-18.

Angle, H. L., \& Lawson, M. B. (1993). Changes in affective and continuance commitment in times of relocation. Journal of Business Research, 26(1), 3-15.

Aranya, N., Kushnir, T., \& Valency, A. (1986). Organizational commitment in a male dominated profession. Human Relations, 39(5), 433-448.

Beck, K., \& Wilson, C. (2000). Development of affective organizational commitment: A crosssequential examination of change with tenure. Journal of Vocational Behavior, 56(1), 114-136.

Campbell, J.P., Dunnett, M.D., Lawler, E.E., \& Weick, K.E. (1970). Managerial Behaviour, Performance and Effectiveness. New York, McGraw-Hill.

Chughtai, A.A., \& Zafar, S. (2006). Antecedents and Consequences of Organizational Commitment among Pakistani University Teachers. Applied H.R.M. Research, 11(1), 39-64.

Decottis, T.A., \& Summers, T.P. (1987). A path analysis of a model of the antecedents and consequences of organisatonal commitment. Human Relations, 40 (7), 495 - 470.

Dey, T. (2012) Predictors of Organizational Commitment and Union Commitment: A Conceptual Study. IUP Journal of Organizational Behavior, 11(4), 62-75.

Gautam, T. (2003). Organizational commitment in Nepal. Unpublished Ph.D. thesis submitted to Faculty of Management, Tribhuvan University, Kathmandu, Nepal.

House, R.J. \& Rizzo, J.R. (1972). Towards the measurement of Organisational Practices: Scale Development and Validation. Applied Psychology, 56(5), 388 - 396.

Ishida, M. (1997). The consequences of organizational commitment. In M. Tao (Ed.), A study of company-man: Theory and practice of organizational commitment. Kyoto: Kyoto University Press. (In Japanese.)

Landry, G. \& Vandenberghe, C. (2009). Role of commitment to the supervisor, leader-member exchange, and supervisor-based self-esteem in employee-supervisor conflicts. The Journal of Social Psychology, 149(1), $5-27$.

Lovakov, A. (2014). Antecedents and Consequences of Organizational Commitment Among Russian University Teachers. SSRN Electronic Journal. DOI: 10.2139/ssrn.2552437

Luthans, F., Baack, D., \& Taylor, L. (1987). Organizational commitment: Analysis of antecedents. Human Relations, 40(4), 219-236.

Madhukar, V., \& Sharma, S. (2017). Organisational climate: A conceptual perspective. International Journal of Management, IT \& Engineering, 7(8), 276-293.

Masuda, K. (1997). The antecedents of organizational commitment. In M. Tao (Ed.), A study of company-man: Theory and practice of organizational commitment. Kyoto: Kyoto University Press. (In Japanese.)

Mathieu, J. E., \& Zajac, D. M. (1990). A review and meta-analysis of the antecedents, correlates, and consequences of organizational commitment. Psychological Bulletin, 108(2), 171-194.

Meyer, J. and Allen, N. (1991) A Three-Component Conceptualization of Organizational Commitment. Human Resources Management Review, 1(1), 81-89.

Meyer, J. P., \& Herscovitch, L. (2001). Commitment in the workplace: Toward a general model. Human Resource Management Review, 11(1), 299-326.

Meyer, J.P. and Allen, N.J. (1997) Commitment in the Workplace: Theory, Research, and Application. 2nd Edition, Sage, Thousand Oaks.

Meyer, J.P., Allen, N.J., \& Smith, S.T. (1993). Affective, continuance and normative commitment to the organization: An examination of construct validity. Journal of Vocational Behaviour, 49(3), 252-276.

Morrow, P. C. (1983). Concept redundancy in organizational research: The case of work commitment. Academy of Management Journal, 8(3), 486-500.

Mowday, R. T., Porter, L. W., \& Steers, R.M., (1982). Employee-organization linkages: the psychology of commitment, absenteeism and turnover. New York: Academic Press. 
O’Reilly, C., \& Chairman, J. (1986). Organizational commitment and psychological attachment: The effects of compliance, identification and internalization on prosocial behavior. Journal of Applied Psychology, 71(3), 492-499.

Pietersen, J. \& Maree, K. (2007). Standardisation of a questionnaire. In K. Maree (Ed.) First Steps in Research (7th ed). Pretoria: Van Schaik Publishers.

Rehman, S., Shareef, A., Mahmood, A. and Ishaque, A. (2012) Perceived Leadership Styles and Organizational Commitment. Interdisciplinary Journal of Contemporary Research in Business, 4(1), 616-626.

Reichers, A. E. (1985). A review and re-conceptualization of organizational commitment. Academy of Management Review, 10(3), 465-476.

Rizzo, J. R., House, R. J., \& Lirtzman, S. I. (1970). Role conflict and ambiguity in complex organizations. Administrative Science Quarterly, 15(2), 150-163.

Schriesheim, C., \& Kerr, S. (1974). Psychometric properties of the Ohio State Leadership scale. Psychological Bulletin, 81(11), 756-765.

Shrestha, P. (2016). Organizational justice and employee work outcomes in service sector of Nepal. Unpublished Ph.D. dissertation submitted to the Faculty of Management, Tribhuvan University, Kathmandu, Nepal.

Shrestha, P. (2019a). Employee commitment and organizational citizenship behavior in Nepal. American International Journal of Business Management (AIJBM), 2(12), 86-90.

Shrestha, P. (2019b). Job involvement and organizational commitment of university faculty members. International Journal of Innovative Research in Science, Engineering and Technology, 8(12), 11572-11579. DOI:10.15680/IJIRSET.2019.0812014

Shrestha, P., \& Parajuli, D. (2020). Comparative functional HRM practices in Nepalese banking and insurance companies. European Journal of Business and Management, 12(30), 1-6.

Singh, A., \& Gupta, B. (2015). Job involvement, organizational commitment, professional commitment, and team commitment. Benchmarking: An International Journal, 22(6), 1192-1211. doi:10.1108/BIJ-01-20140007.

Takagi, H. (1997). What is organizational commitment? Concept and method. In M. Tao (Ed.), A study of company-man: Theory and practice of organizational commitment. Kyoto: Kyoto University Press. (In Japanese.)

Takagi, H., Ishida, M., \& Masuda, K. (1997). A factor structure of company-man. In M. Tao (Ed.), A study of company-man: Theory and practice of organizational commitment. Kyoto: Kyoto University Press. (In Japanese.)

Tao, M., Takagi, H., Ishida, M., \& Masuda, K. (1998). A study of antecedents of organizational commitment. Japanese Psychological Research, 40(4), 198-205.

Witt, L. A., \& Beorkrem, M. N. (1991). Satisfaction with initial work assignment and organizational commitment. Journal of Applied Social Psychology, 21(21), 1783-1792.

Yoon, J., Baker, M. R., \& Ko, J. (1994). Interpersonal attachment and organizational commitment: Subgroup hypothesis revisited. Human Relations, 47(3), 329-351. 